\title{
What shall we do with the damaged proteins in lung disease? Ask the proteasome!
}

\author{
Silke Meiners and Oliver Eickelberg
}

ABSTRACT: The proteasome constitutes the main protein waste disposal and recycling system of the cell. Together with endoplasmic reticulum stress and the autophagosome pathway, it takes centre stage in cellular protein quality control.

In lung research, the proteasome is, first of all, a promising therapeutic target to intervene in the malignant growth of lung cancer cells. Therapeutic targeting of the proteasome has also been extended to pulmonary fibrosis and asthma using animal models. Moreover, the proteasome is involved in lung pathogenesis. In cystic fibrosis, rapid proteasomal degradation of mutant cystic fibrosis transmembrane conductance regulator contributes to loss of function of lung epithelial cells. In chronic obstructive pulmonary disease (COPD), pulmonary proteasome expression and activity are downregulated and inversely correlate with lung function. In addition, as the proteasome degrades signalling mediators that have been oxidatively modified in COPD, it contributes to further compromise cellular function.

The consequences of proteasomal dysfunction are loss of protein quality control, accumulation of misfolded proteins and exacerbation of cellular stress, which are also hallmarks of protein quality diseases and premature ageing. This suggests that proteasome dysfunction can be regarded as a new pathomechanism for chronic lung diseases, awaiting further therapeutic exploration in the future.

KEYWORDS: Cell proliferation control mechanisms, chronic lung disease, epithelial cell biology and pathology, oxygen radicals

hronic lung diseases (CLDs), including chronic obstructive pulmonary disease (COPD), lung cancer, asthma or pulmonary fibrosis, are the second leading cause of death in the world. It is of concern that death rates due to CLD continue to increase, while death rates due to other leading causes of death, such as heart disease, cancer or stroke, are declining [1]. Currently, only limited therapeutic strategies exist to treat CLD, most of which are symptomatic rather than causal. Historically, therapeutic interventions have been designed around the attenuation of specific signalling pathways, such as $G$ protein-coupled receptor activation, interference with transforming growth factor (TGF)- $\beta$ signalling or tyrosine kinase inhibition. Only a few novel therapeutic strategies attempt to intervene with general cellular pathways. Among them, inhibitors of the proteasome interfere with the central protein degradation machinery of the cell.
In clinical research, the proteasome has been shown to present a promising therapeutic target against malignant growth of cancer cells. In 2003, the first clinically applicable proteasome inhibitor, bortezomib, was approved by the US Food and Drug Administration (FDA) for the therapy of relapsed and refractory multiple myeloma [2]. In addition, impaired proteasome function has been associated with protein misfolding diseases, such as neurodegenerative disorders, cardiac and endothelial dysfunction, and cataract formation [3-5]. It is, however, still controversial whether proteasome dysfunction is the chicken or the egg for disease pathogenesis, as pointed out aptly by CIECHANOvER and BRUNDIN [4]. As proteasome research seems to be largely neglected in the lung field except for lung cancer research, we would like to stimulate proteasome research in the lung with this review.

\section{AFFILIATIONS}

Comprehensive Pneumology Center (CPC), University Hospital, Ludwig Maximilians University and Helmholtz Zentrum München, Munich, Germany.

CORRESPONDENCE

S. Meiners

Comprehensive Pneumology Center Ludwig-Maximilians-Universität

Asklepios Klinik Gauting und Helmholtz Zentrum München Max-Lebsche-Platz 31 81377 Munich

Germany

E-mail: silke.meiners@helmholtzmuenchen.de

Received:

Nov 292011

Accepted after revision:

Feb 012012

First published online:

March 222012 


\section{FUNCTION OF THE UBIQUITIN-PROTEASOME SYSTEM}

Every protein that is synthesised needs to be disposed at some point in its life. This is mainly achieved by the proteasome. $\sim 90 \%$ of the cellular proteins are degraded by the ubiquitin-proteasome pathway into small peptides [6]. Proteins can be degraded by the proteasome at different rates with half-lives ranging from minutes to weeks. Proper proteasome function is thus essential for numerous cellular processes, such as protein turnover and quality control, cell growth and cell signalling, immune response and antigen presentation [7-9]. The exceptional biological significance of this protein degradation pathway was publicly acknowledged in 2004, when A. Ciechanover, A. Hershko and I. Rose were awarded the Nobel Prize in Chemistry for their first description of the ubiquitin-proteasome system.

For degradation, proteins are first marked with chains of several ubiquitin molecules [10]. Ubiquitin binds covalently to a specific lysine residue of the substrate via an enzymatic cascade that involves the ubiquitin-activating enzyme E1, an E2 ubiquitinconjugating enzyme and a specific ubiquitin ligase (E3). Subsequently, further ubiquitin moieties are transferred to the previously conjugated ubiquitin molecule. While addition of only single ubiquitin residues to a protein has a sorting and signalling function, tagging of a protein with at least four ubiquitin moieties serves as a degradation signal for the 26S proteasome [11].

The $26 \mathrm{~S}$ proteasome consists of a catalytic core and two regulatory complexes (fig. 1). The 195 regulatory particle with its $>20$ subunits forms a lid- and base-like structure. While the "lid" serves regulatory functions, such as binding of polyubiquitinated proteins and de-ubiquitination of substrates, the "base" mediates energy-dependent unfolding of substrates and "opens the door" to the catalytic core, the $20 \mathrm{~S}$ proteasome. The $20 S$ core has a barrel-like structure with two-fold symmetry (fig. 1): the two outer rings are composed of seven different but related $\alpha$ subunits $(\alpha 1-\alpha 7)$. The two inner rings contain seven different $\beta$ subunits ( $\beta 1-\beta 7)$ [12]. Three of these $\beta$ subunits ( $\beta 1$, $\beta 2$ and $\beta 5$ ) contain catalytic active sites with different cleavage specificities. These catalytic subunits can be exchanged by three inducible subunits, low molecular mass protein (LMP)2, multicatalytic endopeptidase complex subunit (MECL)-1 and LMP7, respectively [8]. These subunits are expressed in response to stimulation of cells with cytokines, namely interferon- $\gamma$, and rapidly assemble into the so-called immunoproteasome, which has altered cleavage site preferences and thus generates a different set of protein degradation products [13].

\section{Protein quality control}

Proper protein function critically depends on the folding of the peptide chain into a complex three-dimensional structure. Protein misfolding arises as a consequence of stress-induced protein modification and denaturation, destabilising missense mutations or a lack of oligomeric assembly partners. In addition, $\sim 30 \%$ of newly synthesised proteins are co-translationally destroyed within minutes of their synthesis by the proteasome. These so-called defective ribosomal products (DRiPs) probably fail to adopt their native conformation, e.g. due to translational errors [14]. A network of chaperones such as heat shock protein (hsp) 40, 70 and 90, and co-chaperones, assist the folding of denatured proteins into their proper functional conformational states [15]. In case chaperones are unable to successfully restore protein folding, the protein is targeted for destruction via

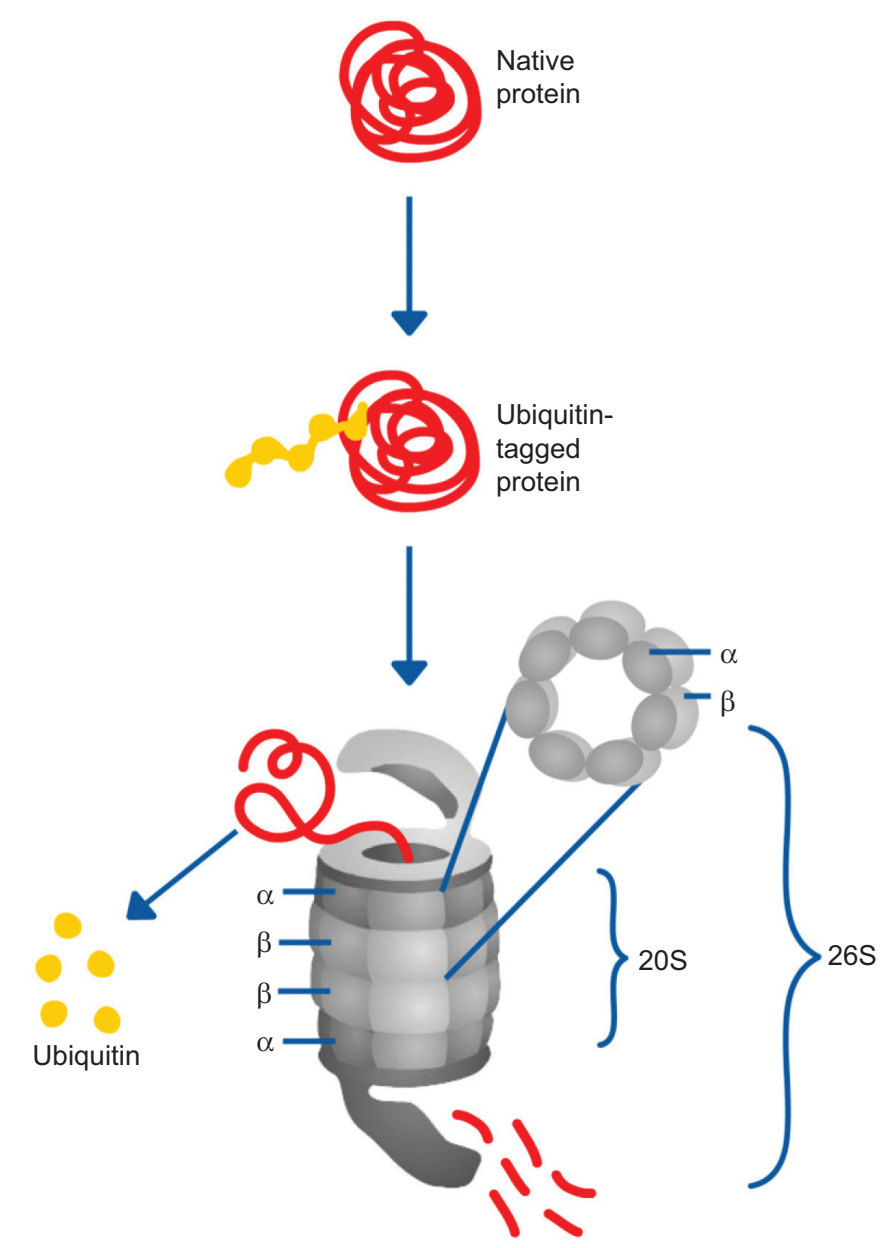

FIGURE 1. Ubiquitin-mediated degradation of proteins. Proteins are tagged with multi-ubiquitin chains and targeted for degradation by the $26 \mathrm{~S}$ proteasome. The $26 \mathrm{~S}$ proteasome consists of a catalytic core, the $20 \mathrm{~S}$ particle and two $19 \mathrm{~S}$ regulatory complexes. Upon binding of the protein substrate to the $26 \mathrm{~S}$ proteasome, ubiquitin chains are recycled, and the protein is unfolded and degraded into small peptide fragments. The 20S core has a barrel-like structure with two outer $\alpha$ and two inner $\beta$ rings consisting of seven different subunits each.

ubiquitin-dependent proteasomal degradation. This concept is known as the protein triage model of protein quality control [16]. The major enzyme for ubiquitination of misfolded proteins is the hsp70-dependent E3-ligase CHIP (carboxy-terminus of hsp70-interacting protein) [17]. There is still some controversy whether degradation of misfolded and modified proteins is strictly dependent on ubiquitination or whether it can take place in the absence of ubiquitination [18, 19]. The ubiquitinproteasome system thus serves as the central quality control system to rapidly destroy misfolded proteins and translational junk. Proteasome-mediated protein quality control, however, appears to be restricted by the solubility of misfolded proteins. While soluble proteins and small soluble protein aggregates are degraded by the proteasome, insoluble aggregates that are sequestered into inclusion bodies or microtubule-associated aggresomes are disposed by autophagy via the lysosomal pathway [20]. Such sequestration of misfolded proteins protects against the proteotoxic effects of unfolded proteins that stick to 
normal proteins, thereby interfering with cellular function [21]. Interestingly, ubiquitin-dependent proteasomal degradation and autophagy are closely linked, as ubiquitinated protein aggregates are recognised by components of the autophagosome [22]. The close interplay of these two cellular disposal machineries is also supported by the observations that impairment of the proteasome is compensated by increased autophagy, but that defective autophagy results in impaired degradation of proteasomal substrates [23].

As approximately one-third of all cellular proteins are targeted to the secretory pathway, the endoplasmic reticulum (ER) protein assembly line needs to be tightly controlled in terms of quality control. The ER offers a specialised form of quality control for secretory proteins. ER-resident chaperones support and supervise folding of secretory proteins. Misfolded ER proteins are tagged with a specific set of sugar moieties within the ER, recognised by resident specialised ubiquitin ligases that span or associate with the ER membrane, and are retrotranslocated into the cytosol for subsequent degradation by the proteasome [24]. This process is termed the ER-associated degradation (ERAD) pathway and complements the unfolded protein response (UPR), a coordinated programme that adjusts the capacity of folding and disposal in the ER [25, 26]. Proteasome function and ER stress response are closely coupled: proteasomes are not only found in close association with the ER membrane but co-translational degradation of ER proteins by the proteasome protects from ER overload [27]. In the opposite case, inhibition of proteasome function induces a terminal UPR in secretory cells that is triggered by the accumulation of misfolded ER proteins due to ERAD dysfunction [28]. The close interplay of ER stress and the proteasome pathway is also reflected by the fact that expression of proteasomal genes and, thus, proteasome function is directly controlled by the ERassociated transcription factor Nrf1 (TCF11) via an ERADdependent feedback loop [29]. In case ERAD efficiency is compromised, autophagy may serve as a backup system for disposal of misfolded and aggregated proteins, as shown for aggregation-prone mutants of $\alpha_{1}$-antitrypsin [30].

The interplay of the ER, proteasome and autophagy pathways as adaptive protein quality control systems of the cell is outlined in figure 2.

\section{Antigen presentation}

The finesse of proteasomal degradation of cellular proteins lies in the fact that the waste products are not simply "lost" but used as a communication system to define the cellular "self" for the immune system. As most of the cellular proteins are at some point degraded by the proteasome either in form of translational junk proteins (DRiPs, see earlier) or at the end of their life as functional proteins, this ensures a stochastic and mean representation of the total cell protein's content in form of short peptides [31]. Peptides are transported into the ER lumen, trimmed by ER-resident protein peptidases, mounted onto major histocompatibility complex (MHC) class I molecules and presented to CD8-positive T-cells. Incorporation of immunoproteasomal subunits results in the preferential generation of peptides with improved binding for MHC I molecules [8]. Tcells that are reactive towards self peptides are eliminated during development of the immune system. In contrast, nonself antigenic peptides are recognised by activated CD8-positive

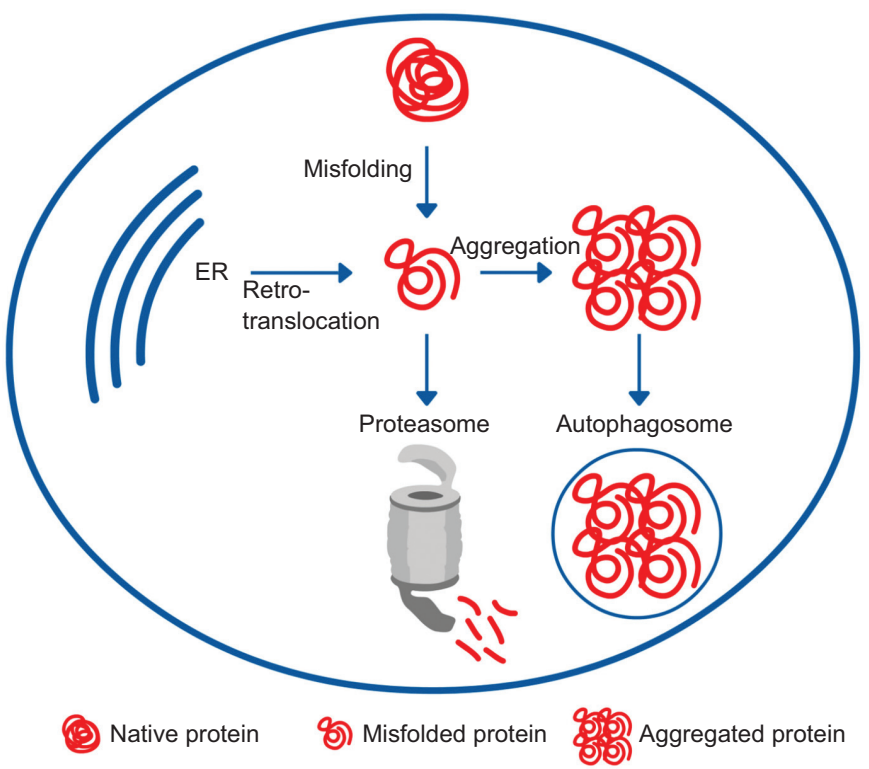

FIGURE 2. Interplay of protein quality control systems within the cell. Cellular protein quality control involves the endoplasmic reticulum (ER) stress pathway, the ubiquitin-proteasome system and autophagy. These pathways are closely interconnected and together serve as an adaptive system for protein disposal within the cell. Cytoplasmic proteins that become misfolded are hydrolysed by the proteasome into small peptides. Misfolded secretory proteins are retrotranslocated from the ER into the cytoplasm where they are degraded by the proteasome. This route is known as the ER-associated degradation pathway. Under certain conditions, misfolded proteins form aggregates that are disposed of by the autophagosome. Disturbance of one or the other protein quality pathway results in accumulation of misfolded proteins within the cell, proteotoxicity and cellular dysfunction.

T-cells and trigger a cytotoxic T-cell-mediated lysis of those cells that are brand-marked with nonself antigenic MHC I peptides. Activation of MHC I-dependent cytotoxic T-cell lysis thus provides an efficient surveillance mechanism for the detection of any cell bearing abnormal genes or proteins, as seen in response to viral infections, tumour antigens and rejection of transplants [32-34]. There is also some evidence that posttranslational modifications of antigenic peptides, such as phosphopeptides, add to the complexity of MHC I-mediated immune responses [35, 36]. Thus, MHC I-mediated antigen presentation may be regarded as a sophisticated form of intercellular communication that not only betrays a foreign or abnormal protein content but may also report signalling dysfunction and stress.

\section{DRUG TARGETING OF THE PROTEASOME}

Inhibitors of the proteasome typically bind to the substratebinding pockets of the $20 \mathrm{~S}$ proteasome and covalently modify the $N$-terminal threonine residues of the catalytically active $\beta$ subunits $\beta 1, \beta 2, \beta 5$ and their inducible counterparts. Most synthetic inhibitors are short peptides with varying pharmacophore groups at their C-terminal end, such as aldehyde, vinyl sulfone or boronate groups. Other inhibitors are drugs derived from natural compounds, such as $\alpha 1, \beta 1$-epoxyketones, syrbactins and $\beta$-lactones [37]. Crystallographic data suggest that the various inhibitors not only differ in their specificity 
and reversibility of active site modifications, but also in their fitting into the specific substrate pockets of the three active sites [38]. This raises the intriguing possibility of generating site specific inhibitors, as recently shown for the immunoproteasome subunit LMP7-specific proteasome inhibitor PR-957 or a specific $\beta 2$-active site inhibitor $[39,40]$. Only recently, a new (reversible and noncovalent) mode of binding was identified for hydroxyurea-based compounds, which specifically inhibit the $\beta 5$ active site of the proteasome [41]. Accumulating evidence suggests that site-specific inhibition of single proteolytic sites of the proteasome affects specific sets of substrates within the cell. This may mediate the observed differential cellular effects in different cell types $[42,43]$. The cell-type-specific effects of the clinically approved inhibitor bortezomib on multiple myeloma compared with solid tumour cells have been attributed to the particular sensitivity of secretory cells to bortezomib-induced UPR induction and apoptosis [28]. A differential and dosedependent degree of inhibition of the three active sites of the proteasome may explain the wide-spread therapeutic applications of bortezomib in mice and humans, not only as anti-tumour but also as anti-fibrotic, anti-inflammatory and anti-hypertrophic drugs [44-47]. The challenge of the future will be to define the cellular responses to specific proteasome inhibitors depending on their degree of active site-specific inhibition to enable defined therapeutic applications of proteasome inhibitors beyond cancer treatment.

\section{PROTEASOME IN CLD}

In the following sections, we will highlight and review the available data on proteasome dysfunction in CLD. This will entail pathways and diseases that have been shown to be affected by proteasome dysfunction. We will also summarise the available data on the use of proteasome inhibitors as a therapeutic drug for CLD. The available data are summarised in table 1 .

\section{Lung cancer}

The timely and controlled degradation of numerous cell cycle regulators, signalling mediators and transcription factors by the proteasomal pathway is essential to ensure proper cell growth and function. Inhibitors of the proteasome block degradation of these signal regulators, thereby inhibiting cell proliferation and inducing apoptosis [62]. Thus, proteasome inhibition was considered a promising cytotoxic approach to combat malignant growth of tumour cells. Several in vitro studies and clinical trials suggest that the FDA-approved inhibitor bortezomib might also be useful as a monotherapy or combinatorial drug to inhibit proliferation of lung tumour cells, sensitise them to apoptosis, reduce the metastatic potential, and to overcome drug resistance in small and non-small cell lung cancer cells, as recently reviewed $[48,49]$. Several second-generation proteasome inhibitors have been developed and are currently under clinical investigation as anti-cancer drugs for haematological malignancies and solid tumours [63]. It is noteworthy that the new proteasome inhibitor NPI-0052 is currently tested in clinical phase I amongst others for therapeutic efficacy in nonsmall cell lung cancer (http: / / clinicaltrials.gov/ct2/show / NCT00461045). Only recently has a different route to interfering with proteasomal protein degradation been taken by inhibiting the activity of de-ubiquitinating enzymes (DUBs). These enzymes are essential for the cleavage and recycling of ubiquitin molecules from substrates preceding their degradation by the proteasome [64]. Blocking DUB activities results in accumulation of polyubiquitinated cellular substrates and has been shown to inhibit cancer growth [65].

Taken together, these data suggest that the proteasome is a highly promising anti-cancer target that can be therapeutically exploited by different means.

\section{Asthma}

Proteasome inhibitors also have potent anti-inflammatory effects due to the diminished activation of the inflammatory transcription factor nuclear factor (NF)- $\mathrm{B}$ [66]. At resting conditions, NF$\kappa \mathrm{B}$ is kept silent by cytoplasmic complexing with its inhibitor $\mathrm{I}-\kappa \mathrm{B}$. Inflammatory signalling, e.g. by tumour necrosis factor $\alpha$ or Toll-like receptor agonists, induces phosphorylation of IкB and its subsequent degradation by the proteasome. NF- $\kappa B$ can then

\section{TABLE 1 Proteasome function in chronic lung disease}

\begin{tabular}{|c|c|c|}
\hline Disease & Effects & References \\
\hline Lung cancer & $\begin{array}{l}\text { Therapeutic application of proteasome inhibitors inhibits lung tumour growth, induces } \\
\text { apoptosis, reduces metastatic potential and overcomes drug resistance }\end{array}$ & {$[48,49]$} \\
\hline \multirow[t]{2}{*}{ Asthma } & Proteasome inhibitors reduce allergen-induced pulmonary eosinophilia in sensitised rats & [50] \\
\hline & $\begin{array}{c}\text { Rationale for proteasome inhibition as a therapeutic approach to counteract NF-kB } \\
\text { signalling in asthma }\end{array}$ & [51] \\
\hline Pulmonary fibrosis & The proteasome inhibitor bortezomib attenuates bleomycin-induced pulmonary fibrosis & [47] \\
\hline \multirow[t]{2}{*}{ Cystic fibrosis } & Proteasomal degradation of mutant CFTR and ENaC via the ERAD pathway & [54-56] \\
\hline & Proteasome inhibition rescues CFTR degradation and partially restores cell function & {$[57,58]$} \\
\hline \multirow[t]{3}{*}{ COPD } & Diaphragm atrophy is associated with increased proteasome activity in COPD patients & [59] \\
\hline & Proteasome inhibition counteracts diaphragm atrophy in mice & {$[60]$} \\
\hline & Downregulation of proteasome expression and activity in lungs of COPD patients & [61] \\
\hline
\end{tabular}


translocate into the nucleus where it transactivates pro-inflammatory genes. Inhibition of the proteasome prevents $\mathrm{I}-\kappa \mathrm{B}$ degradation, inhibits NF- $\kappa \mathrm{B}$ activation and blocks inflammatory gene expression [67]. These anti-inflammatory properties have been exploited to diminish the influx of leukocytes in a model of allergen-induced pulmonary eosinophilia in sensitised rats [50]. The therapeutic targeting of NF- $\mathrm{\kappa B}$ signalling in asthma has been "rediscovered" 10 yrs later in an excellent review by EDWARDS et al. [51]. The recently proposed new paradigm of asthma as a disease initiated by persistent dysfunction of the respiratory epithelium may add a new aspect to proteasome function in this disease with regard to MHC class I antigen presentation [68]. The defective behaviour of the epithelium in response to viral infections and air pollutants may involve alterations in MHC I antigen presentation. Subsequent recruitment of CD8-positive cytotoxic T-cells to the airways will then contribute to epithelial damage as suggested recently in a mouse model of allergic airway inflammation [69]. Thus, it is feasible that this type of immune response contributes to the initiation of epithelial dysfunction and repeated airway damage in virus-mediated exacerbations in asthma. As inhibition of the proteasome has been shown not only to attenuate virus replication in acute lung pneumonitis but also to affect antigenic peptide processing and subsequent cytotoxic T-cell-mediated lysis responses, this may add to the therapeutic potential of proteasome inhibitors in asthma [70, 71]. Only recently, the rationale for therapeutic application of proteasome inhibitors in asthma has been extended to the idea of depleting immunoglobulin-secreting plasma cells. Treatment of ovalbumin-sensitised mice with bortezomib did not, however, attenuate chronic asthma in mice [52].

\section{Pulmonary fibrosis}

Data from cardiac, liver and renal models of fibrosis indicate that nontoxic doses of proteasome inhibitors effectively reduce deposition of collagens, expression of matrix metalloproteinases and TGF- $\beta$ signalling, thereby counteracting development of fibrosis in the respective organs [72]. Accordingly, MuTLu et al. [47] only recently reported that the clinically approved proteasome inhibitor bortezomib promoted normal repair and prevented lung fibrosis after 21 days in bleomycin-treated mice. Importantly, this antifibrotic effect was observed with bortezomib given only twice, on days 7 and 14, after the initial lung damage by bleomycin. In contrast, co-application of both bortezomib and bleomycin resulted in excess mortality in these mice [47]. FINESCHI et al. [53] reported that the daily application of bortezomib starting 1 day after bleomycin instillation did not show any protective effects on the development of bleomycininduced lung fibrosis. These, at first sight, conflicting data may be reconciled by the aforementioned notion that the divergent cellular effects of proteasome inhibitors ranging from cytotoxic to anti-inflammatory and anti-fibrotic have been shown to be dose- and cell type-dependent, and are strongly determined by the degree of proteasome inhibition in the target cell type: sustained inhibition of the proteasome induces apoptosis, while partial inhibition is nontoxic and exerts beneficial effects [42, 43, 73]. Accordingly, inhibition of the proteasome to a defined degree is crucial to achieve a desired therapeutic effect in a particular disease. While sustained inhibition and cytotoxic effects are desirable in the setting of lung cancer, it might be adverse in other CLDs such as asthma and pulmonary fibrosis. Partial inhibition of the proteasome, however, exerts anti-inflammatory and anti-fibrotic effects in the absence of toxicity [74, 75]. For that reason, it is of major importance to carefully monitor the degree of proteasome inhibition in the particular cell type and animal model used, and adjust the dose of inhibitor correspondingly.

\section{Cystic fibrosis}

The prominent role of the proteasome in cystic fibrosis is well known and has been covered by several excellent reviews [76-78]. Proteasomal degradation of both the cystic fibrosis transmembrane conductance regulator (CFTR) and the epithelial $\mathrm{Na}^{+}$channel is part of the ERAD system for disposal of misfolded ER proteins involving polyubiquitination and retrotranslocation of these proteins into the cytosol, as described earlier [54,55]. Again, inhibition of the proteasome has been proposed as a strategy to rescue degradation of rapidly degraded CFTR folding mutants (specifically the $\triangle 508$ CFTR mutant), to counteract inflammation and partially restore ion currents in the respiratory epithelium [57]. Only recently have proteasome inhibitors been used for nanoparticle-based targeted drug delivery in a mouse model for cystic fibrosis [58]. Loss of functional CFTR has been associated with intracellular aggregate formation, accumulation of polyubiquitinated proteins and aberrant autophagy in lung epithelial cells [79]. It needs to be further investigated whether proteasome function is also impaired in CFTR-aberrant cells, as was shown for mutant surfactant protein $C$ and aggregated neuronal proteins [80-83]. Such a scenario is very reminiscent of protein quality diseases of the brain and heart, where reduced proteasome activity exaggerates cellular stress and contributes to a vicious cycle of cellular dysfunction $[3,4]$.

\section{COPD}

Proteasome function has been investigated in COPD patients and corresponding mouse models with regard to lung remodelling and diaphragm atrophy.

Diaphragm muscle atrophy in COPD patients correlated with increased expression and activity of the ubiquitin-proteasome system [59, 84, 85]. This finding was further substantiated by animal experiments where proteasome inhibitors efficiently counteracted increased protein turnover in a model for diaphragm atrophy, indicating a causal role for increased proteasome activity for diaphragm atrophy [60]. The data are in accordance with previous reports on enhanced proteasome activity at conditions of increased muscle turnover in cachexia and cardiac hypertrophy [86, 87]. In contrast, proteasome expression and activity are downregulated in the lungs of COPD patients and inversely correlate with lung function [61]. In this study by MALHOTRA et al. [61], reduced expression of proteasomal subunits was associated with decreased expression of the antioxidant transcription factor Nrf2 in the lungs of COPD patients. However, while patients' data suggested a direct correlation between smoking and emphysema status of the patients with diminished proteasome function, cigarette smokeexposed and emphysematous mice showed increased proteasome expression and activity, suggesting an adaptive response of the lung to cigarette smoke-induced stress. Despite these conflicting data, the concept of proteasome dysfunction contributing to COPD disease progression is in agreement with the observed changes in proteasome activity in protein quality 


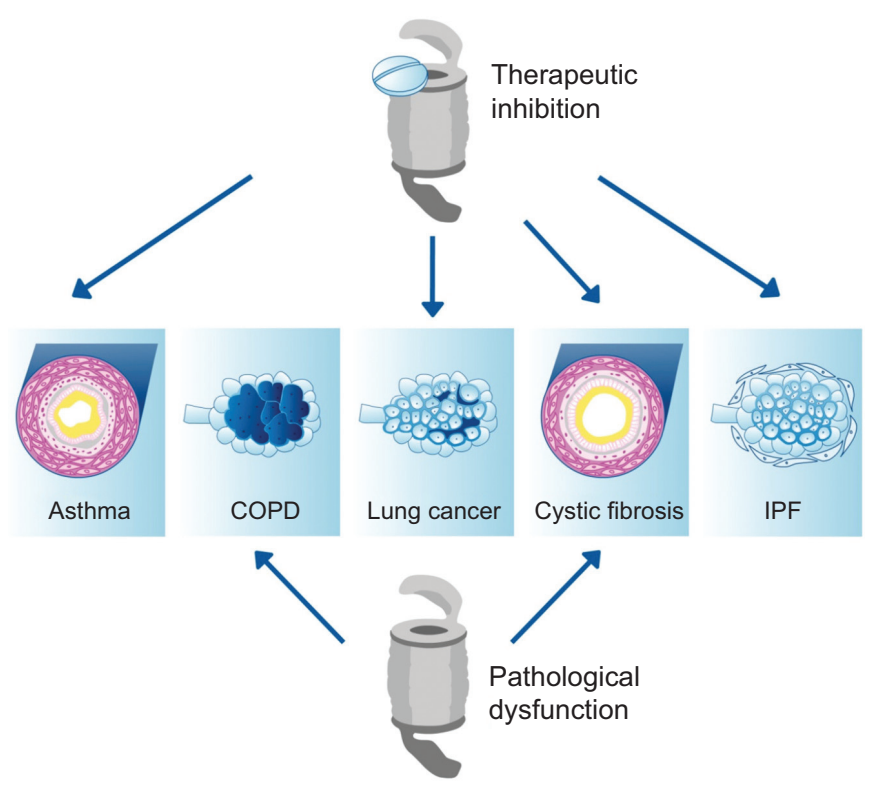

FIGURE 3. Proteasome function in chronic lung disease: therapeutic target and pathological dysfunction. Proteasome inhibitors have been successfully applied for the treatment of asthma, cystic fibrosis, idiopathic pulmonary fibrosis (IPF) and lung cancer in animal models and clinical studies. Proteasome function has been shown to be relevant for cystic fibrosis and chronic obstructive pulmonary disease (COPD) pathogenesis.

diseases, as outlined previously. As the proteasome takes centre stage in the degradation of oxidatively modified and misfolded proteins, it is reasonable to assume that cigarette smoke challenges the proteolytic capacity of this system. Accordingly, a number of studies have demonstrated the importance of proteasomal degradation of modified and misfolded proteins in response to cigarette smoke exposure: oxidative modification of histone modifying enzymes, such as histone deacetylase 2 and sirtuin 1 as well as of signalling mediators, such as interferon- $\gamma$ and vascular endothelial growth factor-receptor, Akt kinase, glutaredoxin-1 and the NF-kB family member relB, impairs the function of these molecules and makes them prone to proteasomal degradation [88-96]. The consequences of the nontimely degradation of central signalling mediators and the accompanying impairment of epigenetic, oxidative, inflammatory and growth factor signalling for the pathogenesis of COPD are evident and have been excellently reviewed elsewhere [97-99].

Cigarette smoke-mediated oxidative modification and loss of function may also apply to the protein quality control system itself, such as the proteasome. Indeed, oxidative modification and impaired proteasome function have been observed in several cell culture models and in patients with myocardial infarction or neurodegenerative disorders $[100,101]$. One might speculate that chronic oxidative stress, as seen in COPD, affects proteasome function in the lung, which ultimately tips the balance from an adaptive stress response of lung cells to a vicious cycle of detrimental accumulation of oxidatively modified proteins, cellular dysfunction and cell death. A scenario of decreased proteasome function in COPD is also fully in line with the concept of accelerated ageing of the lung in response to chronic oxidative stress, as loss of proteasome activity has been identified as a strong and independent marker for ageing [102-106].

\section{CONCLUDING REMARKS}

In summary, there is accumulating evidence for a central role of proteasome function in chronic lung disease (fig. 3): on the one hand, the proteasome is a feasible target for therapeutic intervention in lung disease beyond its sole application in lung cancer. On the other hand, alterations in proteasome function in the lung emerge as a new pathomechanism for chronic lung diseases. The consequences of proteasomal dysfunction are deleterious as the central protein recycling machinery of the cell is affected. This results in accumulation of protein waste within the single cell and exacerbation of cellular stress. A second and currently neglected aspect of proteasome function is related to its role in MHC I antigen presentation. As the products of proteasomal degradation are employed for communication purposes to report the immune system about foreign or abnormal proteins, it is feasible that mutated or modified proteins are differentially processed by impaired proteasome activity and result in the generation of nonself antigenic MHC I epitopes that betray the stressed cell to the immune system. This may then represent some form of communication to the immune system, such as "Houston, we have a problem!"

\section{STATEMENT OF INTEREST}

None declared.

\section{ACKNOWLEDGEMENTS}

We are grateful to S. van Rijt (Comprehensive Pneumology Center, Munich, Germany) for stimulating discussions and critically reading the manuscript.

\section{REFERENCES}

1 American Lung Association, 2008. www.lung.org/assets/documents/ publications/lung-disease-data/LDD_2008.pdf Date last accessed: August 29, 2012.

2 Bross PF, Kane R, Farrell AT, et al. Approval summary for bortezomib for injection in the treatment of multiple myeloma Clin Cancer Res 2004; 10: 3954-3964.

3 Schlossarek S, Carrier L. The ubiquitin-proteasome system in cardiomyopathies. Curr Opin Cardiol 2011; 26: 190-195.

4 Ciechanover A, Brundin P. The ubiquitin proteasome system in neurodegenerative diseases: sometimes the chicken, sometimes the egg. Neuron 2003; 40: 427-446.

5 Dahlmann B. Role of proteasomes in disease. BMC Biochemistry 2007; 8: S3.

6 Rock KL, Gramm C, Rothstein L, et al. Inhibitors of the proteasome block the degradation of most cell proteins and the generation of peptides presented on MHC class I molecules. Cell 1994; 78: 761-771.

7 Bader M, Steller H. Regulation of cell death by the ubiquitinproteasome system. Curr Opin Cell Biol 2009; 21: 878-884.

8 Kloetzel PM, Ossendorp F. Proteasome and peptidase function in MHC-class-I-mediated antigen presentation. Curr Opin Immunol 2004; 16: 76-81.

9 Goldberg AL. Protein degradation and protection against misfolded or damaged proteins. Nature 2003; 426: 895-899.

10 Finley D. Recognition and processing of ubiquitin-protein conjugates by the proteasome. Annu Rev Biochem 2009; 78: 477-513.

11 Koegl M, Hoppe T, Schlenker S, et al. A novel ubiquitination factor, E4, is involved in multiubiquitin chain assembly. Cell 1999; 96: 635-644.

12 Groll M, Ditzel L, Lowe J, et al. Structure of $20 \mathrm{~S}$ proteasome from yeast at $2.4 \AA$ resolution. Nature 1997; 386: 463-471. 
13 Strehl B, Seifert U, Krüger E, et al. Interferon- $\gamma$, the functional plasticity of the ubiquitin-proteasome system, and MHC class I antigen processing. Immunol Rev 2005; 207: 19-30.

14 Schubert U, Anton LC, Gibbs J, et al. Rapid degradation of a large fraction of newly synthesized proteins by proteasomes. Nature 2000; 404: 770-774.

15 Morimoto RI. Proteotoxic stress and inducible chaperone networks in neurodegenerative disease and aging. Genes Dev 2008; 22: $1427-1438$.

16 Wickner S, Maurizi MR, Gottesman S. Posttranslational quality control: folding, refolding, and degrading proteins. Science 1999; 286: 1888-1893.

17 Rosser MF, Washburn E, Muchowski PJ, et al. Chaperone functions of the E3 ubiquitin ligase CHIP. J Biol Chem 2007; 282: 22267-22277.

18 Medicherla B, Goldberg AL. Heat shock and oxygen radicals stimulate ubiquitin-dependent degradation mainly of newly synthesized proteins. J Cell Biol 2008; 182: 663-673.

19 Shringarpure R, Grune T, Mehlhase J, et al. Ubiquitin conjugation is not required for the degradation of oxidized proteins by proteasome. J Biol Chem 2003; 278: 311-318.

20 Kaganovich D, Kopito R, Frydman J. Misfolded proteins partition between two distinct quality control compartments. Nature 2008; 454: 1088-1095.

21 Kopito RR. Aggresomes, inclusion bodies and protein aggregation. Trends Cell Biol 2000; 10: 524-530.

22 Kirkin V, McEwan DG, Novak I, et al. A role for ubiquitin in selective autophagy. Mol Cell 2009; 34: 259-269.

23 Korolchuk VI, Mansilla A, Menzies FM, et al. Autophagy inhibition compromises degradation of ubiquitin-proteasome pathway substrates. Mol Cell 2009; 33: 517-527.

24 Vembar SS, Brodsky JL. One step at a time: endoplasmic reticulum-associated degradation. Nat Rev Mol Cell Biol 2008; 9: 944-957.

25 Hirsch C, Gauss R, Horn SC, et al. The ubiquitylation machinery of the endoplasmic reticulum. Nature 2009; 458: 453-460.

26 Ron D, Walter P. Signal integration in the endoplasmic reticulum unfolded protein response. Nat Rev Mol Cell Biol 2007; 8: 519-529.

27 Oyadomari S, Yun C, Fisher EA, et al. Cotranslocational degradation protects the stressed endoplasmic reticulum from protein overload. Cell 2006; 126: 727-739.

28 Obeng EA, Carlson LM, Gutman DM, et al. Proteasome inhibitors induce a terminal unfolded protein response in multiple myeloma cells. Blood 2006; 107: 4907-4916.

29 Steffen J, Seeger M, Koch A, et al. Proteasomal degradation is transcriptionally controlled by TCF11 via an ERAD-dependent feedback loop. Mol Cell 2010; 40: 147-158.

30 Perlmutter DH. The role of autophagy in alpha-1-antitrypsin deficiency: a specific cellular response in genetic diseases associated with aggregation-prone proteins. Autophagy 2006; 2: 258-263.

31 Yewdell JW, Reits E, Neefjes J. Making sense of mass destruction: quantitating MHC class I antigen presentation. Nat Rev Immunol 2003; 3: 952-961.

$32 \mathrm{Li} \mathrm{XC,} \mathrm{Raghavan} \mathrm{M.} \mathrm{Structure} \mathrm{and} \mathrm{function} \mathrm{of} \mathrm{major} \mathrm{histocom-}$ patibility complex class I antigens. Current Opin Organ Transplant 2010; 15: 499-504

33 Townsend AR, Gotch FM, Davey J. Cytotoxic T cells recognize fragments of the influenza nucleoprotein. Cell 1985; 42: 457-467.

34 Vigneron N, Van den Eynde BJ. Insights into the processing of MHC class I ligands gained from the study of human tumor epitopes. Cell Mol Life Sci 2011; 68: 1503-1520.

35 Engelhard VH, Altrich-Vanlith M, Ostankovitch M, et al. Posttranslational modifications of naturally processed MHC-binding epitopes. Curr Opin Immunol 2006; 18: 92-97.

36 Mohammed F, Cobbold M, Zarling AL, et al. Phosphorylationdependent interaction between antigenic peptides and MHC class I: a molecular basis for the presentation of transformed self. Nature Immunol 2008; 9: 1236-1243.

37 Groll M, Huber R, Moroder L. The persisting challenge of selective and specific proteasome inhibition. J Pept Sci 2009; 15: 58-66.

38 Borissenko L, Groll M. 20S proteasome and its inhibitors: crystallographic knowledge for drug development. Chem Rev 2007; 107: 687-717.

39 Muchamuel T, Basler M, Aujay MA, et al. A selective inhibitor of the immunoproteasome subunit LMP7 blocks cytokine production and attenuates progression of experimental arthritis. Nat Med 2009; 15: 781-787.

40 Mirabella AC, Pletnev AA, Downey SL, et al. Specific cellpermeable inhibitor of proteasome trypsin-like sites selectively sensitizes myeloma cells to bortezomib and carfilzomib. Chem Biol 2011; 8: 608-618.

41 Gallastegui N, Beck P, Arciniega M, et al. Hydroxyureas as noncovalent proteasome inhibitors. Ang Chemie Internat Ed 2012; 51: 247-249.

42 Meiners S, Ludwig A, Stangl V, et al. Proteasome inhibitors: poisons and remedies. Med Res Rev 2008; 28: 309-327.

43 Kisselev AF, Callard A, Goldberg AL. Importance of the different proteolytic sites of the proteasome and the efficacy of inhibitors varies with the protein substrate. J Biol Chem 2006; 281: 8582-8590.

44 Lonial S, Mitsiades CS, Richardson PG. Treatment options for relapsed and refractory multiple myeloma. Clin Canc Res 2011; 17: 1264-1277.

45 Palombella VJ, Conner EM, Fuseler JW, et al. Role of the proteasome and NF- $\kappa \mathrm{B}$ in streptococcal cell wall-induced polyarthritis. Proc Natl Acad Sci USA 1998; 95: 15671-15676.

46 Meiners S, Dreger H, Fechner M, et al. Suppression of cardiomyocyte hypertrophy by inhibition of the ubiquitinproteasome system. Hypertension 2008; 51: 302-308.

47 Mutlu GM, Budinger GR, Wu M, et al. Proteasomal inhibition after injury prevents fibrosis by modulating TGF- $\beta 1$ signalling. Thorax 2012; 67: 139-146.

48 Escobar M, Velez M, Belalcazar A, et al. The role of proteasome inhibition in nonsmall cell lung cancer. J Biomed Biotechnol 2011; 2011: 806506.

49 Davies AM, Lara PN Jr, Mack PC, et al. Incorporating bortezomib into the treatment of lung cancer. Clin Cancer Res 2007; 13: s4647-s4651.

50 Elliott PJ, Pien CS, McCormack TA, et al. Proteasome inhibition: a novel mechanism to combat asthma. J Allergy Clin Immunol 1999; 104: 294-300.

51 Edwards MR, Bartlett NW, Clarke D, et al. Targeting the NF- $\mathrm{BB}$ pathway in asthma and chronic obstructive pulmonary disease. Pharmacol Ther 2009; 121: 1-13.

52 Wegmann M, Lunding L, Orinska Z, et al. Long-term bortezomib treatment reduces allergen-specific $\operatorname{IgE}$ but fails to ameliorate chronic asthma in mice. Intern Arch Allergy Immunol 2011; 158: 43-53.

53 Fineschi S, Bongiovanni M, Donati $\mathrm{Y}$, et al. In vivo investigations on anti-fibrotic potential of proteasome inhibition in lung and skin fibrosis. Am J Respir Cell Mol Biol 2008; 39: 458-465.

54 Morito D, Hirao K, Oda Y, et al. Gp78 cooperates with RMA1 in endoplasmic reticulum-associated degradation of CFTR $\Delta$ F508. Mol Biol Cell 2008; 19: 1328-1336.

55 Buck TM, Kolb AR, Boyd CR, et al. The endoplasmic reticulumassociated degradation of the epithelial sodium channel requires a unique complement of molecular chaperones. Mol Biol Cell 2010; 21: 1047-1058.

56 Ward CL, Omura S, Kopito RR. Degradation of CFTR by the ubiquitin-proteasome pathway. Cell 1995; 83: 121-127. 
57 Belcher CN, Vij N. Protein processing and inflammatory signaling in cystic fibrosis: challenges and therapeutic strategies. Curr Mol Med 2010; 10: 82-94.

58 Vij N, Min T, Marasigan R, et al. Development of PEGylated PLGA nanoparticle for controlled and sustained drug delivery in cystic fibrosis. J Nanobiotech 2010; 8: 22-26.

59 Ottenheijm CA, Heunks LM, Li YP, et al. Activation of the ubiquitin-proteasome pathway in the diaphragm in chronic obstructive pulmonary disease. Am J Respir Crit Care Med 2006; 74: 997-1002.

60 van Hees H, Ottenheijm C, Ennen L, et al. Proteasome inhibition improves diaphragm function in an animal model for COPD. Am J Physiol Lung Cell Mol Physiol 2011; 301: L110-L116.

61 Malhotra D, Thimmulappa R, Vij N, et al. Heightened endoplasmic reticulum stress in the lungs of patients with chronic obstructive pulmonary disease: the role of Nrf2-regulated proteasomal activity. Am J Respir Crit Care Med 2009; 180: 1196-1207.

62 Adams J. The development of proteasome inhibitors as anticancer drugs. Cancer Cell 2004; 5: 417-421.

63 Dick LR, Fleming PE. Building on bortezomib: second-generation proteasome inhibitors as anti-cancer therapy. Drug Discov Today 2010; 15: 243-249.

64 Reyes-Turcu FE, Ventii KH, Wilkinson KD. Regulation and cellular roles of ubiquitin-specific deubiquitinating enzymes. Annu Rev Biochem 2009; 78: 363-397.

65 D'Arcy P, Brnjic S, Olofsson MH, et al. Inhibition of proteasome deubiquitinating activity as a new cancer therapy. Nat Med 2011; 17: $1636-1640$.

66 Palombella VJ, Rando OJ, Goldberg AL, et al. The ubiquitinproteasome pathway is required for processing the NF-kappa B1 precursor protein and the activation of NF-kappa B. Cell 1994; 78 773-785.

67 Karin M, Ben Neriah Y. Phosphorylation meets ubiquitination: the control of NF-кB activity. Annu Rev Immunol 2000; 18 621-663.

68 Holgate ST. Has the time come to rethink the pathogenesis of asthma? Curr Opin Allergy Clin Immunol 2010; 10: 48-53.

69 Aguilar-Pimentel JA, Alessandrini F, Huster KM, et al. Specific CD8 T cells in IgE-mediated allergy correlate with allergen dose and allergic phenotype. Am J Respir Crit Care Med 2010; 181: 7-16.

70 Ma XZ, Bartczak A, Zhang J, et al. Proteasome inhibition in vivo promotes survival in a lethal murine model of severe acute respiratory syndrome. J Virol 2010; 84: 12419-12428.

71 Schwarz K, de Giuli R, Schmidtke G, et al. The selective proteasome inhibitors lactacystin and epoxomicin can be used to either up- or down-regulate antigen presentation at nontoxic doses. J Immunol 2000; 164: 6147-6157.

72 Weiss CH, Budinger GR, Mutlu GM, et al. Proteasomal regulation of pulmonary fibrosis. Proc Am Thor Soc 2010; 7: 77-83.

73 Lin KI, Baraban JM, Ratan RR. Inhibition versus induction of apoptosis by proteasome inhibitors depends on concentration. Cell Death Differ 1998; 5: 577-583.

74 Ludwig A, Fechner M, Wilck N, et al. Potent anti-inflammatory effects of low-dose proteasome inhibition in the vascular system. J Mol Med 2009; 87: 793-802.

75 Meiners S, Hocher B, Weller A, et al. Downregulation of matrix metalloproteinases and collagens and suppression of cardiac fibrosis by inhibition of the proteasome. Hypertension 2004; 44 471-477.

76 Turnbull EL, Rosser MF, Cyr DM. The role of the UPS in cystic fibrosis. BMC Biochem 2007; 8: S11.

77 Rotin D, Staub O. Role of the ubiquitin system in regulating ion transport. Eur J Physiol 2011; 461: 1-21.

78 Kopito RR. Biosynthesis and degradation of CFTR. Physiol Rev 1999; 79: S167-S173.
79 Luciani A, Villella VR, Esposito S, et al. Defective CFTR induces aggresome formation and lung inflammation in cystic fibrosis through ROS-mediated autophagy inhibition. Nat Cell Biol 2010; 12: 863-875.

80 Lindersson E, Beedholm R, Hojrup P, et al. Proteasomal inhibition by alpha-synuclein filaments and oligomers. J Biol Chem 2004; 279: 12924-12934.

81 Bence NF, Sampat RM, Kopito RR. Impairment of the ubiquitinproteasome system by protein aggregation. Science 2001; 292: 1552-1555.

82 Mulugeta S, Nguyen V, Russo SJ, et al. A surfactant protein C precursor protein BRICHOS domain mutation causes endoplasmic reticulum stress, proteasome dysfunction, and caspase 3 activation. Am J Respir Cell Mol Biol 2005; 32: 521-530.

83 Cheroni C, Marino M, Tortarolo M, et al. Functional alterations of the ubiquitin-proteasome system in motor neurons of a mouse model of familial amyotrophic lateral sclerosis. Hum Mol Genet 2009; 18: 82-96.

84 Testelmans D, Crul T, Maes K, et al. Atrophy and hypertrophy signalling in the diaphragm of patients with COPD. Eur Respir J 2010; 35: 549-556.

85 Vogiatzis I, Simoes DCM, Stratakos G, et al. Effect of pulmonary rehabilitation on muscle remodelling in cachectic patients with COPD. Eur Respir J 2010; 36: 301-310.

86 Depre C, Wang Q, Yan L, et al. Activation of the cardiac proteasome during pressure overload promotes ventricular hypertrophy. Circulation 2006; 114: 1821-1828.

87 Hobler SC, Williams A, Fischer D, et al. Activity and expression of the $20 \mathrm{~S}$ proteasome are increased in skeletal muscle during sepsis. Am J Physiol 1999; 277: R434-R440.

88 Khan EM, Lanir R, Danielson AR, et al. Epidermal growth factor receptor exposed to cigarette smoke is aberrantly activated and undergoes perinuclear trafficking. FASEB J 2008; 22: 910-917.

89 Huang Fu WC, Liu J, Harty RN, et al. Cigarette smoking products suppress anti-viral effects of Type I interferon via phosphorylation-dependent downregulation of its receptor. FEBS Lett 2008; 582: 3206-3210.

90 Osoata GO, Yamamura S, Ito M, et al. Nitration of distinct tyrosine residues causes inactivation of histone deacetylase 2 . Biochem Biophys Res Comm 2009; 384: 366-371.

91 Adenuga D, Yao H, March TH, et al. Histone deacetylase 2 is phosphorylated, ubiquitinated, and degraded by cigarette smoke. Am J Respir Cell Mol Biol 2009; 40: 464-473.

92 Kim SY, Lee JH, Huh JW, et al. Cigarrette smoke induces AKT degradation by the ubiquitin proteasome system. J Biol Chem 2011; 286: 31932-31943.

93 Yang SR, Yao H, Rajendrasozhan S, et al. RelB is differentially regulated by IкB kinase- $\alpha$ in B cells and mouse lung by cigarette smoke. Am J Respir Cell Mol Biol 2009; 40: 147-158.

94 Caito S, Rajendrasozhan S, Cook S, et al. SIRT1 is a redoxsensitive deacetylase that is post-translationally modified by oxidants and carbonyl stress. FASEB J 2010; 24: 3145-3159.

95 Edirisinghe I, Arunachalam G, Wong C, et al. Cigarette-smokeinduced oxidative/nitrosative stress impairs VEGF- and fluidshear-stress-mediated signaling in endothelial cells. Antiox Redox Signal 2010; 12: 1355-1369.

96 Kuipers I, Guala AS, Aesif SW, et al. Cigarette smoke targets glutaredoxin 1, increasing S-glutathionylation and epithelial cell death. Am J Respir Cell Mol Biol 2011; 45: 931-937.

97 Yao H, Rahman I. Current concepts on oxidative/carbonyl stress, inflammation and epigenetics in pathogenesis of chronic obstructive pulmonary disease. Toxicol Appl Pharmacol 2011; 254 72-85.

98 Barnes PJ, Adcock IM, Ito K. Histone acetylation and deacetylation: importance in inflammatory lung diseases. Eur Respir J 2005; 25: 552-563. 
99 Rahman I, Adcock IM. Oxidative stress and redox regulation of lung inflammation in COPD. Eur Respir J 2006; 28: 219-242.

100 Cecarini V, Ding Q, Keller JN. Oxidative inactivation of the proteasome in Alzheimer's disease. Free Rad Res 2007; 41: 673-680.

101 Predmore JM, Wang P, Davis F, et al. Ubiquitin proteasome dysfunction in human hypertrophic and dilated ardiomyopathies. Circulation 2010; 121: 997-1004.

102 MacNee W. Accelerated lung aging: a novel pathogenic mechanism of chronic obstructive pulmonary disease (COPD). Biochem Soc Trans 2009; 37: 819-823.
103 Tuder RM. Aging and cigarette smoke: fueling the fire. Am J Respir Crit Care Med 2006; 174: 490-491.

104 Chondrogianni N, Gonos ES. Proteasome dysfunction in mammalian aging: steps and factors involved. Exp Gerontol 2005; 40: 931-938.

105 Ito K, Barnes PJ. COPD as a disease of accelerated lung aging. Chest 2009; 135: 173-180.

106 Karrasch S, Holz O, Jorres RA. Aging and induced senescence as factors in the pathogenesis of lung emphysema. Respir Med 2008; 102: $1215-1230$. 